\section{Галазова С.C.}

д-р экон. наук, ФГБОУ ВО

«Северо-осетинский государственный университет имени К. Л. Хетагурова», г. Владикавказ

e-mail: bubu1999@mail.ru

\section{Магомаева Л.Р.}

канд. экон. наук, ФГБОУ ВО «Грозненский государственный нефтяной технический университет имени акад. М. Д. Миллионщикова», г. Грозный

e-mail: rumanovna@gmail.com

\section{Новые вызовы и проблемы финансового рынка в условиях системы открытого банка}

\begin{abstract}
Аннотация
Раскрыты основные тенденции развития мирового финансового рынка в условиях активного роста открытого цифрового банкинга, определяющего новые возможности и вызовы для создания инновационных банковских и финансовых продуктов. Рассмотрены ключевые стадии «финансовой репрессии", предопределившей новые вызовы и проблемы для традиционной модели финансового рынка. Обоснованы основные трудности и проблемы, связанные с переходом от традиционной модели банкинга к модели open banking standard. В анализе доказано, что дальнейшее развитие финансового рынка диктует необходимость увеличения эффективности и снижения издержек при разработке цифровых сервисов следующего поколения. В данной связи повсеместное внедрение open banking standard позволит создавать новые продукты для финансового рынка. Внедрение open banking standard в режиме реального времени позволит открыть доступ для потребителя к более персонализированным информационным ресурсам, а услуги будут предоставляться через безопасный открытый сервис с целью более эффективного управления личными финансами. Сегодня множество малых и средних компаний для ведения бухгалтерской отчетности используют сторонние коммерческие разработки, однако транзакционные данные им приходится вводить вручную. Практическое использование open banking standard позволит потребителю не только получать данные в режиме реального времени, но и отчасти решит проблему получения доступа к более персонализированным информационным ресурсам для принятия банковских решений. Также клиентам можно будет предложить лучшие условия ссуд, поскольку кредитные организации смогут проанализировать его транзакционные данные для определения уровня риска заемщика.
\end{abstract}

Ключевые слова:

открытый банкинг, фринансовый рынок, банковская система, прибыль клиентской базы, информационный ресурс, продукт и услуга.

\section{New challenges and problems of the financial market in the open bank system conditions}

Abstract

The main trends in the development of the global financial market in conditions of active development of open digital banking, which determines new opportunities and challenges for the creation of innovative banking and financial products are revealed. The key stages of "financial repression", which predetermined new challenges and problems for the traditional model of the financial market, are considered. The main difficulties and problems connected with the transition from the traditional banking model to the Open Banking Standard model are substantiated. The analysis proves that further development of the financial market dictates the need to increase efficiency and reduce costs in the development of next-generation digital services. In this regard, the widespread introduction of Open Banking Standard will create new products for the financial market. The implementation of Open Banking Standard in real time will allow to open access for the consumer to more personalized information resources, and services will be provided through a secure open service in order to more effectively manage personal finances. Today, many small and mediumsized companies use third-party commercial development for accounting purposes, but they have to enter transaction data manually. The practical use of Open Banking Standard will allow the consumer not only to receive data in real time, but will also partially solve the problem of gaining access to more personalized information resources for making banking decisions. Also, clients will be able to offer better loan terms, as credit institutions will be able to analyze its transaction data to determine the level of the borrower's risk.

Keywords:

open banking, financial market, banking system, profit of the client base, informational resource; product and service.

(C) The Author(s), 2018 This is an open access article under the CC BY 4.0 license (http://creativecommons. org/licenses/by/4.0/)

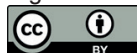

В последние годы возможности роста и инновационного развития мировой экономики предопределяют новые технологии, активно внедряемые в структуры финансового рынка. С подобными выводами вполне согласны некоторые эксперты, полагая, что современное развития институтов финансового рынка невозможно без использования новаторских подходов, что связано с реструктуризацией модели мировой экономики, требующей применения новых комбинаций, где информационным системам уделено особое внимание, поскольку они являются важнейшим звеном между поставщиками 
и получателями финансовых ресурсов [4]. В научной и деловой литературе в последние годы приобретает популярность термин «комбинаторность» информационных ресурсов, т. е. использование различных источников информации в целях увеличения темпа экономического роста [8].

Сегодня развитие интернета открывает новые возможности как для людей, так и для компаний во всем мире. Однако не все в равной степени извлекают выгоды из этого. Экономические выгоды или «цифровые дивиденды», связанные с развитием интернета, нередко получают те, кто обладает более высокими доходами, востребованными навыками или находится в более благоприятной среде.

Такое положение дел может привести к росту неравенства как внутри стран, так и между ними. В последнем докладе Всемирного банка «Получение цифровых дивидендов» обращается внимание на необходимость применения надлежащих мер экономической политики, поскольку цифровые активы в финансовом секторе могут стать движущей силой сокращения бедности и обеспечения всеобщего развития стран Европы и Центральной Азии (далее - ЕЦА) [10].

Основные трудности, с которыми сталкиваются сегодня страны ЕЦА, связаны с глубоким неприятием изменений, обусловленных новыми информационными технологиями. Неприятие изменений проявляется в виде сопротивления развитию информационных платформ, поддерживающих экономику совместного потребления, наблюдаемого в более развитых экономиках запада региона. Интернет, как и большинство технологических изменений, может повлечь за собой разрушение привычного положения вещей, однако его потенциальные выгоды намного превосходят издержки. Вместо того чтобы защищать существующие рабочие места за счет сопротивления новым технологиям, государственные органы могли бы сосредоточить меры на поддержке тех, кто лишился работы и ищет новые возможности трудоустройства; вместо попыток контролировать информацию «сверху-вниз» сегодня используются меры, направленные на извлечение преимуществ из инноваций «снизу-вверх», открывающиеся благодаря улучшению доступа в интернет и к «большим данным».

Опыт развитых стран показывает, что почти повсеместный и доступный выход в интернет - далеко не универсальное средство для появления устойчивой экономики, основанной на интернет-технологиях. Так, в развитых экономиках ЕЦА выручка от электронной торговли вносит меньший вклад в валовой внутренний продукт (далее - ВВП), чем в США и Японии. Причина низкого уровня электронной торговли в странах Европейского Союза (далее - ЕС) кроется отнюдь не в плохом доступе в интернет, такой результат может быть объяснен сопутствующими факторами, такими как отсутствие доверия к финансовой системе, опасения по поводу кибербезопасности или жесткими нормами регулирования.

Важно учитывать, что недостаточность развития финансовой системы, ее информационная слабость может являться не только причиной низкого экономического роста, но и возможностью возникновения «финансовой репрессии» [прим. автора: термин финансовая репрессия употребляется в контексте стадий разрушения традиционной финансовой системы], под которой подразумевается разрушение традиционной кредитно-финансовой системы, обусловленной изменением в потреблении клиентов.

На сегодняшний день в научной и деловой литературе принято выделять 4 ключевые стадии репрессии традиционной кредитно-финансовой системы: - широкое развитие интернет технологий и социальных сетей - предопределяет расширение предложения для покупателей финансовой услуги. Чем выше степень развития, тем больше возможностей для расширения продуктового инструментария финансового рынка;

- наличие персонифицированного финансового сервиса, под которым в первую очередь подразумевается использование индивидуальных средств коммуникаций, выполняющих функцию платежной системы; - использование мобильных средств оплаты за товары и услуги, что определяет отказ клиентов от традиционного банкинга (например, мобильные кошельки и безконтактные средства платежа);

- уход клиентов от использования традиционного банковского счета в конкретном банке или небанковской кредитной организации и его замена на виртуальные счета, позволяющие совершить транзакции без использования функций финансового посредника.

В рамках указанных ключевых стадий финансовой репрессии, предопределившей новые вызовы и проблемы для традиционной модели финансового рынка, рассмотрим последовательно каждую из них.

Так, первая стадия, ознаменованная появлением интернет технологий на глобальном финансовом рынке, определила изменение общих подходов и принципов обслуживания клиентов и их доступа к финансовым ресурсам. Достаточно сказать, что наряду с возможными угрозами стабильности кредитно-финансовой системы появились новые способы и возможности использования платежей и расчетов, что кардинально изменило и психологическое поведение потенциальных потребителей, в первую очередь за счет появления ранее недоступных сервисов и способов совершения операций. 
С развитием интернета появился новый импульс для развития транзакционного бизнеса на дистанционной основе. Интернет, по сути стал главным катализатором изменения потребительского спроса и предпочтения на продукты и услуги финансового рынка.

По окончании первой стадии стали возникать новые каналы - социальные сети, которые фактически изменили представление банков и других финансовых посредников о потенциальных способах их применения. Социальные сети формируют не только портрет потенциального клиента, но и дают возможность их использовать для осуществления финансовых операций. Фактически с момента появления социальных сетей стал формироваться новый взгляд на персонифицированный финансовый сервис, что и послужило началу развития новой, второй стадии, определившей возможности к использованию индивидуальных средств коммуникаций, выполняющих функцию платежной системы.

Большинство специалистов сходятся во мнении о том, что в ближайшем будушем банки потеряют большую часть своих привычных функций в пользу компаний мобильной связи, альтернативных систем расчетов или разнообразных мобильных средств расчетов, в связи с этим банковские услуги станут функцией, не привязанной к банку [7]. Однако на сегодняшний день глобальная финансовая система остается центральным звеном, увязывающим различные бизнес-направления в единую систему расчетов, предоставляя отдельные неперсонифицированные услуги, например, управления инвестициями. Если традиционные банки не смогут использовать новую информационную систему финансового рынка, воспринимая Интернет и мобильный банкинг не в качестве побочных каналов продаж, а как основу бизнеса, то их ждут грандиозные сокращения персонала и потеря прибыли.

Третья стадия репрессии традиционной кредитнофинансовой системы была обусловлена отказом большинства потребителей от традиционного банкинга в виду более активного использования мобильных средств оплаты за товары и услуги. Именно эта стадия спровоцировала развития технологического процесса в финансовой индустрии. Необходимо учитывать, что технологический прогресс набирает обороты, что обусловлено значительным сокращением среднего временного промежутка от изобретения технологии до ее массового внедрения. Например, такая социальная сеть, как Facebook, стала популярной всего за два года своего существования, а для самолетостроения этот показатель когда-то составил 68 лет. С нашей точки зрения, от скорости внедрения новых технологий путем активного использования информационной системы зависит доля охвата финансового рынка и возможности развития конкуренции.

В чем же состоит механизм трансформация современной информационной системы? Во-первых, изменение традиционных средств связи на средства финансовых коммуникаций. Во-вторых, частичный отказ от использования традиционного банкинга, а впоследствии полный отказ от функций финансовых посредников. В-третьих, превращение информации в ценнейший актив финансового рынка.

Таким образом, мы подошли к важнейшей, четвертой стадии репрессии кредитно-финансовой системы, которая, с нашей точки зрения, пока носит начальный характер и не проникает во все сферы финансовой деятельности. Безусловно, использование виртуальных счетов отчасти уже затронуло клиентский бизнес частных лиц, однако требования отечественного и зарубежного законодательства, регулирующего глобальный финансовый сектор, пока не предусматривают возможности полного отказа от использования классического расчетного счета, что предопределяет возможности для сохранения ниши традиционного банкинга, однако сегмент моментальных платежей и расчетов уже полностью охвачен технологиями бесконтактных платежей.

Странами-пионерами перехода к безналичному обороту денег являются страны Евросоюза. Несмотря на то, что в Европе нет единой, принятой Брюсселем, политики, направленной на отмену наличного денежного оборота - cashless society, определенное давление сверху все же присутствует. Так, недавно было предложено отказаться от использования купюры в пятьсот евро, однако с нашей точки зрения без общеевропейских директив стремительное движение к отказу от оборота монет и банкнот и полному переходу на безналичный денежный оборот наблюдается в большинстве развитых стран Еврозоны.

Согласно статистике, во Франции больше $50 \%$ розничных платежей безналичны, в Нидерландах $52 \%$, а Хорватии удалось достичь показателя в $90 \%$ [6]. Сегодня активно развиваются и альтернативные криптовалюты, не управляемые регулятором ни одной страны, именно поэтому крупнейшие платежные системы мира, такие как Visa и MasterCard, уже осознали угрозу своей деятельности и начали активную интеграцию своей инфраструктуры с сервисами мобильных платежей, а также развитие альтернативных средств финансовых расчетов.

Поэтому с нашей точки зрения, репрессия мировой кредитно-финансовой системы будет определять скорость внедрения новых информационных технологий, которые кардинально изменят 
состояние финансового сектора, его будущее и дальнейшие перспективы развития.

Несмотря на свой потенциал, стремительное развитие новых информационных технологий в кредитно-финансовой системе определяет перспективу возникновения новых проблем и уязвимостей ввиду недостаточности или отсутствия альтернативных систем безопасности в бизнес-моделях; отсутствия защиты в использовании персональных данных; проблем в выявлении электронных способов мошенничества и пр.

Таким образом, развитие глобальной кросс-канальной информационной системы сегодня предопределено различными интеграционными процессами, происходящими на мировом финансовом рынке. В условиях тотальной информатизации кредитнофинансовых институтов возрастает необходимость развития дополнительного контроля для обеспечения национальной безопасности, что связано с необходимостью решения следующих основных проблем [9]: - недостаточной рентабельностью кредитных и финансовых организаций, обусловленной низкой отдачей инвестиций или прибыли от собственного капитала;

- завышенными ожиданиями потребителей, связанными с развитием дистанционных технологий и сервисом для обеспечения необходимого качества обслуживания;

- повышением конкуренции со стороны компаний, занимающихся финансовыми технологиями. Растущая популярность fintech-компаний нарушает равновесие сложившейся инфраструктуры финансового рынка, что создает проблемы и трудности для традиционных банков, поскольку они не могут быстро адаптироваться к изменениям не только в области технологий, но также в операциях, культуре и других аспектах деятельности;

- повышением регуляторных требований ввиду того, что банкам приходится тратить значительную часть своего дискреционного бюджета на их соответствие, а также на разработку систем и процессов их развития с учетом растущих потребностей клиентов.

Учитывая растущие вызовы и проблемы финансового рынка в условиях развития кросс-канальной информационной системы, возникает необходимость использования альтернативной и более адаптированной системы, соответствующей запросам рынка.

В научной и деловой литературе подобная система получила название «Открытый банк» - open banking, в основе которой лежит объединением и комбинация различных финансовых услуг с использованием общего интерфейса для повышения качества клиентского обслуживания [3].
Во-первых, основным отличием традиционного и открытого банка является возможность использования информационных данных сторонними компаниями или организациями для цели их защиты и последующего анализа, что значительно расширяет возможности для использования передовых финансовых технологий в условиях перехода к цифровому банкингу. Во-вторых, использование системы открытого банка позволяет использовать социальные сети и делать их основным каналом коммуникаций с клиентом, что значительно снижает затраты на операционное обслуживание. Таким образом, «большие данные» уже не являются сторонним компонентом финансового рынка, а создают встроенный процесс, определяя совместную модель развития банковских и финансовых технологий между несвязанными и неаффилированными между собой сторонами для предоставления расширенных возможностей внешних и внутренних клиентов.

Потенциальные преимущества открытого банковского дела существенны: улучшенный опыт работы с клиентами, новые потоки доходов и устойчивая модель обслуживания для традиционно недостаточно обслуживаемых рынков. Б. Т. Моргоев обращает внимание на необходимость развития и обновления модели существующей мировой банковской системы, однако важно учитывать, что наряду с неоспоримыми преимуществами системы «Открытого банка» модель его развития несет в себе существенные риски, прежде всего сконцентрированные в области обмена данных, что определяет необходимость разработки новых управленческих и контрольных процессов на основе технических связей [2]. Подобную точку зрения разделяет и М. А. Биганова, полагая, что в зависимости от выбранной специфики корпоративного контроля должны создаваться адекватные механизмы реагирования на внешние угрозы [1].

Идеологическая концепция системы «Открытого банка» состоит не только в изменении региональной, но и в мировой модели операционной деятельности и бизнес-модели, что предопределяет дальнейшее развитие и эволюционирование банковской и финансовой деятельности.

Следуя этой концепции, все мировые банки сегодня должны изменить свою структуру, бизнес-архитектуру, они должны сделать цифровые технологии основой своей системы, а также осуществить переход от традиционного банка к новому банку будущего. Для того, чтобы успешно реализовать данную концепцию, банкам необходимо сформировать собственное видение дальнейшей деятельности, изменить стратегию и команду для дальнейшего развития. Иными словами, open banking [прим. автора: open banking 
может быть реализован на основе платежной директивы PSD2, открывающей доступ банков к своей платежной и расчетной системам через участие третьих лиц] представляет собой не теоретические положения развития будущего банковской и финансовой деятельности, а является мировой стратегией развития на ближайшие десятилетия с целью успешной конкуренции c fintech-компаниями и ассоциациями.

Неоспоримым конкурентным преимуществом банков является их история, опыт и наследие, формирующая доверие со стороны реальных клиентов и потребителей их услуг.

У банков есть история - это их бренд и доверие к ним, а также клиенты, наследие и опыт. Fintechкомпании не обладают данным преимуществом, однако именно они сегодня создают для рынка лучшие банковские и финансовые продукты, что определяет идеальные условия для сотрудничества, но не для конкуренции.

В научной и деловой литературе сегодня часто возникают дискуссии о возможности создания новой модели финансового сектора, идеально сочетающего финансовые и технологические возможности, однако в практической деятельности эта задача не выполнима. Например, в европейских странах, несмотря на высокую концентрацию банков, большая часть из них исчезнет, не выдержат конкуренции с высокотехнологичными крупными банками. Подобная ситуация определяет и возможности дальнейшего развития страхового рынка, тесно связанного с банковскими и кредитными организациями.

В России, в отличие от развитых стран, концентрация государственного капитала в страховом и банковском секторе находится на уровне 70-75\%, что определяет вектор развития в будущем. В Европейских странах и странах Азии показатель участия государственного капитала в финансовом секторе не превышает 10-15\%, определяя новые стимулы для их мотивации и маневра входящих в него компаний в будущем.

Например, уже в 2019 г. в Великобритании запланирован ввод нового стандарта - open banking standard для банков открытого типа. В целом можно отметить, что в последние годы развитие банковской индустрии определило ряд последовательных шагов для повышения клиентской удовлетворенности и межбанковской конкуренции наряду со снижением стоимости операционного обслуживания.

Основная причина такого активного развития банковской индустрии заключается в смене парадигмы развития финансового рынка в целом. Так, в 2013 г. уже был сформирован новый сервис для банков, позволяющий сравнивать условия в различных банках и при необходимости менять провайдера - фи- нансового посредника для их предоставления. Однако данный сервис не получил поддержки со стороны потребителей, в связи с чем регулятор при поддержке крупнейших банков выдвинул инициативу open banking standard в надежде дать клиентам больше контроля над своими финансами и знаний о них.

Внедрение open banking standard в режиме реального времени позволит открыть доступ для потребителя к более персонализированным информационным ресурсам, а услуги будут предоставляться через безопасный открытый сервис с целью более эффективного управления личными финансами. Сегодня множество малых и средних компаний для ведения бухгалтерской отчетности используют сторонние коммерческие разработки, однако транзакционные данные им приходится вводить вручную. Практическое использование open banking standard позволит потребителю не только получать данные в режиме реального времени, но и отчасти, решит проблему получения доступа к более персонализированным информационным ресурсам для принятия банковских решений. Также клиентам можно будет предложить лучшие условия ссуд, ведь кредитные организации смогут проанализировать его транзакционные данные для определения уровня риска заемщика.

В Германии open bank project существует с 2010 г. и уже работает с крупнейшими немецкими банками над созданием экосистемы сторонних приложений для клиентов. В Европе инициатива открытого банка поддерживается регуляторами в связи с вступлением в силу новой Европейской платежной директивы (PSD2), а с в январе 2016 г. банки обязаны будут обеспечить доступ третьих сторон к транзакционной информации. Директива дает клиентам возможность использовать информационные онлайн-сервисы, получающие консолидированную информацию об их платежных счетах, вне зависимости от того, есть ли договор между информационным и финансовым провайдерами.

Однако внедрение подобных примеров нельзя пока назвать массовыми для некоторых мировых стран, включая США. Некоторые банки в США отказываются раскрывать транзакционную информацию сторонним компаниям по причине высокой нагрузки на инфраструктуру. В число таких банков вошли, к примеру, J. P. Morgan и Wells Fargo. Однако данную мотивировку можно рассматривать и как стратегический ход для возможной защиты от экспансии fintech-компаний в целях защиты внутреннего банковского и финансового рынка.

Вместе с тем следует признать, что идеи внедрения открытого банкинга сегодня чрезвычайно востребованы практически на всех сложившихся 
мировых финансовых рынках, включая рынки развивающихся стран.

Например, в Латинской Америке всего 51 \% взрослого населения имеют банковские счета, так что вместо продвижения способов сменить банк там необходимо сфокусироваться на индивидуально предложении востребованного продукта людям, заинтересованным в финансовых сервисах. Исследования, проводимые в Чили и Мексике, показывают, что мобильные платежные приложения вряд ли смогут стать альтернативой классических наличных денег, однако внедрение на развивающихся рынках инициатив open banking standard позволит увеличить банковскую клиентскую базу и предоставить потребителю доступ к кредитам, инвестиционным возможностям и иным продуктам [5].

В заключении отметим, что новые вызовы в развитии мирового финансового рынка в условиях от- крытого цифрового банкинга определяют новую роль в развитии информационных технологий и открывает новые возможности сторонним организациям для разработки инновационных банковских и финансовых продуктов. Необходимо учитывать, что дальнейшее развитие финансового рынка определяет необходимость увеличения эффективности и снижения издержек при разработке цифровых сервисов следующего поколения. Поэтому повсеместное внедрение open banking standard позволит создавать новые продукты для финансового рынка, что приведет к увеличению количества новых банковских сервисов и сокращению времени вывода их на рынок.

Будущее цифрового банкинга стоит за продуктивной конкуренцией между провайдерами услуг, безопасным обменом данными и предоставлением клиентам все большего числа возможностей по управлению финансами.

\section{Библиографический список}

1. Биганова, М. А. Исследование специфики рынка корпоративного контроля в РФ / М. А. Биганова, С. С. Ашкалов, Новоселова Н. Н. // Вестник Института дружбы народов Кавказа Теория экономики и управления народным хозяйством. - 2015. - № 3 (35). - С. 6.

2. Моргоев, Т. Б. Неравномерность рыночной корпоратизации банковского сектора в РФ / // Финансы региона. - 2007. - 6 (45). - С. 143-148.

3. Осипов, Д. С. Тенденции развития банковского сектора и модернизация кредитных продуктов / Д.С. Осипов // Банковское кредитование. - 2013. - № 4. - С. 87-96.

4. Сухарев, О. С. Теория реструктуризации экономики. М.: Ленанд, 2016. - С. 256.

5. Сухарев, О. С. Управление экономикой. Введение в теорию кризисов и роста. - М.: Финансы и статистика, 2012. - С. 286.

6. Цветков, В. А. Экономический рост России: новая модель управления / В. А. Цветков, О.С. Сухарев. - М.: Ленанд, 2017. - С. 352.

7. Обмен данными в условиях открытого банкинга [Электронный ресурс]. - Режим доступа: https://www. mckinsey.com/industries/ (дата обращения: 20.05.2018).

8. Официальный сайт Евростат: [Электронный ресурс]. Режим доступа: http://ec.europa.eu/eurostat/statisticsexplained/index.php/Category:Archive___digital_ economy_and_society (дата обращения: 25.05.2018).

9. Bloom, N. Measuring Economic Policy Uncertainty / N. Bloom, S. Baker, S. Davis / The quarterly journal of economics. - 2016. - November.

10. Reaping Digital Dividends: Leveraging the Internet for Development in Europe and Central Asia [Электронный peсурс]. - Режим доступа: http://www.vsemirnyjbank. $\mathrm{org} / \mathrm{ru} / \mathrm{region} / \mathrm{eca} /$ publication/digital-dividends-in-eca (Дата обращения 28.05.2018).

\section{References}

1. Biganova M. A., Ashkalov S. S., Novosyolova N. N. Issledovanie specifiki rynka korporativnogo kontrolya v RF [Study of the specifics of the corporate control market in Russia]. Vestnik Instituta druzhby narodov Kavkaza Teoriya ehkonomiki i upravleniya narodnym hozyajstvom [Bulletin Of the Institute of friendship of peoples of the Caucasus Theory of Economics and management of national economy], 2015, I. 3 (35), p. 6.

2. Morgoev T. B. Neravnomernost' rynochnoj korporatizacii bankovskogo sektora v RF [Uneven market corporatization of the banking sector in Russia]. Finansy regiona [Regional Finance], 2007, I. 6 (45), pp. 143-148.

3. Osipov D. S. Tendencii razvitiya bankovskogo sektora i modernizaciya kreditnyh produktov [Trends in the banking sector and modernization of credit products]. Bankovskoe kreditovanie [Bank credit], 2013, I. 4, pp. 87-96.

4. Suharev O. S. Teoriya restrukturizacii ehkonomiki [Theory of economic restructuring]. M.: Lenand, 2016, p. 256.

5. Suharev O. S. Upravlenie ehkonomikoj. Vvedenie v teoriyu krizisov i rosta [Economic management. Introduction to the theory of crises and growth]. Finansy i statistika, 2012, p. 286.

6. Cvetkov V. A., Suharev O. S. EHkonomicheskij rost Rossii: novaya model' upravleniya. [Russia's economic growth: a new management model]. M.: Lenand, 2017. p. 352.

7. Obmen dannymi v usloviyah otkrytogo banking [Data exchange in open banking]. Available at: https://www. mckinsey.com/industries/ (accessed 20.05.2018).

8. Oficial'nyj sajt Evrostat [The official website of Eurostat]. Available at: http://ec.europa.eu/eurostat/statisticsexplained/index.php/Category:Archive_-_digital_ economy_and_society (accessed 25.05.2018).

9. Bloom N., Baker S., Davis S. Measuring Economic Policy Uncertainty // The quarterly journal of economics. November, 2016.

10. Reaping Digital Dividends: Leveraging the Internet for Development in Europe and Central Asia. Available at: http://www.vsemirnyjbank.org/ru/region/eca/publication/ digital-dividends-in-eca (accessed 28.05.2018). 